(C) NIAB 2018. This is an Open Access article, distributed Plant Genetic Resources: Characterization and Utilization (2018) 16(6); 498-503 under the terms of the Creative Commons Attribution licence (http://creativecommons.org/licenses/by/ doi:10.1017/S1479262118000072 4.0/), which permits unrestricted re-use, distribution, and reproduction in any medium, provided the original work is properly cited.

ISSN 1479-2621

\title{
Variation in floret size explains differences in wild bee visitation to cultivated sunflowers
}

\author{
Zoe M. Portlas ${ }^{1,2}$, Jonathan R. Tetlie ${ }^{3}$, Deirdre Prischmann-Voldseth ${ }^{2}$, Brent S. Hulke ${ }^{1}$ and \\ Jarrad R. Prasifka ${ }^{1}$ * \\ ${ }^{1}$ Red River Valley Agricultural Research Center, USDA-ARS, 1605 Albrecht Boulevard North, Fargo, ND \\ 58102-2765, USA, ${ }^{2}$ Department of Entomology, North Dakota State University, NDSU Department 7650, \\ Fargo, ND 58108-6050, USA and ${ }^{3}$ Department of Entomology, University of Illinois at Urbana-Champaign, \\ 505 South Goodwin Avenue, Urbana, IL 61801, USA
}

\section{Received 21 November 2017; Accepted 16 February 2018 - First published online 15 March 2018}

\begin{abstract}
Wild and managed bees are needed to move sunflower (Helianthus annuus L.) pollen, both to create hybrid seed and to encourage high, consistent yields when those hybrids are subsequently grown. Among floral traits that influence bee preference, floret size may be critical, as the depth of the corolla affects the accessibility of nectar. Sampling and observation of inbred maintainer (HA) lines were used to assess variation in floret size, and to measure any effects of floret size on pollinator visitation. Among 100 inbreds sampled, there was significant variation among the lines, with floret lengths of $6.8-9.9 \mathrm{~mm}$. Floret length, measured before anthesis, was closely related to corolla depth during anthesis and was consistent between 2 years (environments). Pollinator observations on 30 inbred lines showed floret size explained a majority $(52 \%)$ of the variation in wild bee preference, with a reduction in floret length of $2 \mathrm{~mm}$ more than doubling pollinator activity. Though honey bee, Apis mellifera $\mathrm{L}$., colonies were located $\approx 60 \mathrm{~m}$ from the plots, near-zero honey bee activity in the sunflowers precluded an assessment of how strongly this managed pollinator is affected by floret length. Production of inbreds and hybrids with smaller florets could enhance sunflower pollination, but genetic markers for floret size are needed to facilitate selection, and an understanding of potential trade-offs also is required. Information on variation and heritability of other traits, such as pollen and nectar rewards, could help explain residual variation in wild bee visitation to sunflowers.
\end{abstract}

Keywords: Andrena helianthi Robertson, Asteraceae, ecosystem services, Helianthus annuus L., Melissodes trinodis Robertson, pollination

\section{Introduction}

Sunflower, Helianthus annuus L., is among the top global oilseed crops, with an average production of 40-50 million tonnes per year (FAO, 2017). Genetic self-incompatibility is common in wild sunflowers, creating a dependence on insects, especially bees, to move pollen in order to produce

*Corresponding author. E-mail: jarrad.prasifka@ars.usda.gov seed (Heiser et al., 1969). Though selection in cultivated sunflower has increased self-compatibility (Gandhi et al., 2005), there are at least two reasons bees remain indispensable to the crop. First, because modern sunflowers use a hybrid system based on cytoplasmic male sterility (CMS), hybrid seed production is completely reliant on bees to move pollen from male-fertile to male-sterile parental lines (DeGrandi-Hoffman and Watkins, 2000; Greenleaf and Kremen, 2006). Second, even for self-compatible hybrids, stressful conditions during bloom can limit yields 
(via self-pollination) in the absence of bees (DeGrandiHoffman and Chambers, 2006). Honey bees (Apis mellifera L.) are used as a managed pollinator for production of hybrid seed, but wild bees also contribute directly and indirectly to pollination of sunflowers (DeGrandi-Hoffman and Watkins, 2000; Greenleaf and Kremen, 2006; Nderitu et al., 2008).

Bees often show distinct preferences for certain sunflower inbreds and hybrids (Tepedino and Parker, 1982; Cerrutti and Pontet, 2016; Mallinger and Prasifka, 2018). Pollinator preferences in cultivated sunflowers have been associated with several traits, including pollen availability (Tepedino and Parker, 1982; Mallinger and Prasifka, 2017), nectar content or composition (Neff and Simpson, 1990; Pham-Delegue et al., 1990), floral odor (PhamDelegue et al., 1990) and floret size (or corolla depth; du Toit and Coetzer, 1991; Mallinger and Prasifka, 2017). All of these traits may be important in some instances, and differences among pollinators add to the complexity of determining how traits enhance pollinator visitation. For example, Tepedino and Parker (1982) noted that while honey bees preferred CMS inbred lines with little or no pollen, wild bees preferred male-fertile sunflowers. This difference in pollen preference also was observed by Mallinger and Prasifka (2017), who excluded other possible causes by using pairs of sunflower isolines with or without CMS. Though the contrast between honey bees and wild bees likely reflects a basic difference in life-histories (i.e. social, and long-lived, honey bees often stop collecting pollen periodically based on need [Camazine, 1993]), it underscores the fact that not all pollinator species will have the same responses to variation in plant traits.

Floret size may be the most attractive trait for further research because it should be relatively easy to measure, may affect other traits important to pollinators (e.g. by physically limiting access to nectar) and is supported by observations in other plant-pollinator systems (Inouye, 1980; Peat et al., 2005). As part of an ongoing effort to explore the potential for improved sunflower-pollinator interactions, floret samples and field observations were used to assess (1) variation in floret size among female inbred sunflower lines, (2) the relationship between overall floret size and corolla depth, (3) possible environmental effects on floret size and (4) the effect of floret size differences on preferences of wild and managed bees.

\section{Materials and methods}

\section{Variation in floret size and relationship to corolla depth}

To assess variation in the size of sunflower florets, samples were taken from 100 public inbred lines in the USDA-ARS breeding nursery in Glyndon, Minnesota, in 2016. At this location, 8 ha of sunflowers (inbreds, hybrids and entries from segregating populations) were grown in single-row plots $(6 \mathrm{~m})$ with $0.76 \mathrm{~m}$ between rows and an average of $0.30 \mathrm{~m}$ between plants in a plot. Floret sampling focused on single-headed maintainer lines (designated 'HA'), representing the female heterotic group in sunflowers (as opposed to branched male 'RHA' lines). On the first or second day of anthesis (i.e. pollen shed) for heads in the selected inbred lines, a small wedge (or sector) was cut from each of up to five heads per plot, and the wedges were stored frozen $\left(-20^{\circ} \mathrm{C}\right)$ until flowering of all lines was complete. Wedges were processed using forceps to pluck five open florets (with corolla open and anther tube exserted) and five closed (pre-anthesis) florets, which were placed into microcentrifuge tubes and returned to the freezer prior to imaging and analysis. Images for all of the closed florets for each line were obtained using a flatbed scanner with the lid removed but covered by a box to contrast lighter florets with a uniformly dark background. Each TIFF image (600 dpi) was subsequently processed using a macro in Image (Schneider et al., 2012) to automatically measure the total length (called Feret diameter in ImageJ) of individual florets. Examples of scanned florets and images after processing are shown in Fig. 1.

The approach of measuring florets described above uses total floret length as a proxy for corolla depth, which more accurately indicates the proboscis ('tongue') length needed for a pollinator to access nectar from the base of the corolla. The proxy was used because without removing the anther tube of each open floret by hand, there appeared to be no simple way to obtain accurate, automated measures of corolla depth. Consequently, to determine the relationship between floret length and corolla depth, open florets from a random subsample of the lines $(n=30)$ were also scanned and corolla depth measured by hand in ImageJ.

\section{Floret size and interactions with environment and pollinator visitation}

Based on floret size data from the 2016 planting, groups of inbred lines with relatively short or long florets $(n=15 \mathrm{HA}$ lines for each group) and similar maturity (i.e. days from planting to anthesis) were selected for planting at the USDA-ARS sunflower entomology plot on the NDSU Agronomy Seed Farm in Casselton, North Dakota, in 2017. This location comprised 0.4 ha of single-row plots similar to those in the 2016 breeding nursery. The 30 lines were planted in two randomized complete blocks approximately $60 \mathrm{~m}$ away from four commercial honey bee hives. To assess possible environmental effects on floret size, samples were taken from the first replicate for each of the lines, which were processed and analysed for total 


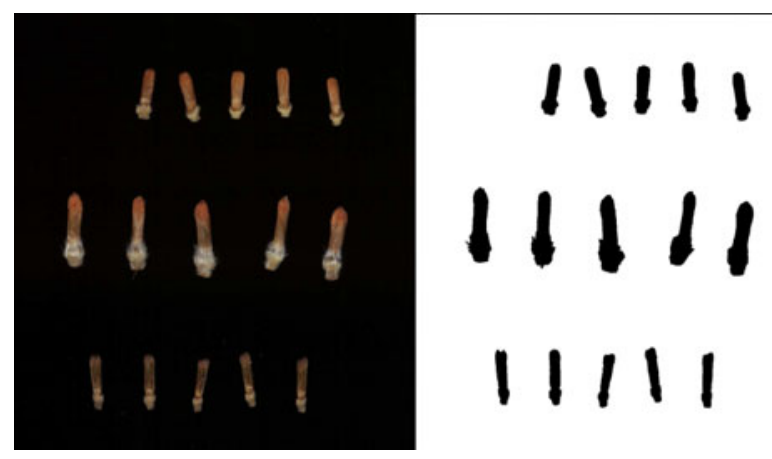

Fig. 1. Examples of scanned florets and processed images used for floret size measurements. Florets shown include the shortest inbred line measured (HA 341, at top), the longest (HA 286, middle) and a locally-collected wild sunflower (bottom).

floret length as in 2016. Additionally, to test for effects of floret size on pollinator visits, observations were made during bloom in each of the 60 plots. After the number of blooming plants per plot was counted, once or twice each day a 1-min pollinator observation was made in each plot with $>3$ blooming plants. Observations were typically made the late morning (11:00 AM) or early afternoon (1:00 PM), and continued over ten days. Separate counts of honey bees, bumble bees, and other wild bees were recorded for each plot.

\section{Statistical analyses}

All analyses were performed using SAS (SAS Institute Inc., 2016). An analysis of variance (ANOVA; PROC GLM) was used to assess whether mean floret length differed significantly among sunflower maintainer lines sampled in 2016. Post-ANOVA means separation used Dunnett's test to compare 99 other inbred lines with HA 441 (PI 639164; Miller and Gulya, 2006), which had the shortest corollas among 10 maintainer lines measured by Mallinger and Prasifka (2017). A simple linear regression was used (PROC REG) with 2016 data to determine whether total (closed) floret length measured automatically from scanned images is a suitable proxy for corolla depth (on open florets) measured by hand. Similarly, possible effects of the year or site variation were assessed by regressing (PROC REG) average floret length of inbred lines for 2017 onto values for the same lines in 2016. Because pollinator counts are influenced by the number of plants observed, total visits of bees to each inbred line were adjusted for the total number of blooming plants for each line overall observations. This adjustment summarized pollinator attraction to each inbred line as a number of bees per 100 plant observations. Though the pollinator visitation experiment was intended to compare two discrete groups (short and long florets), observed floret size data from 2017 were more continuously

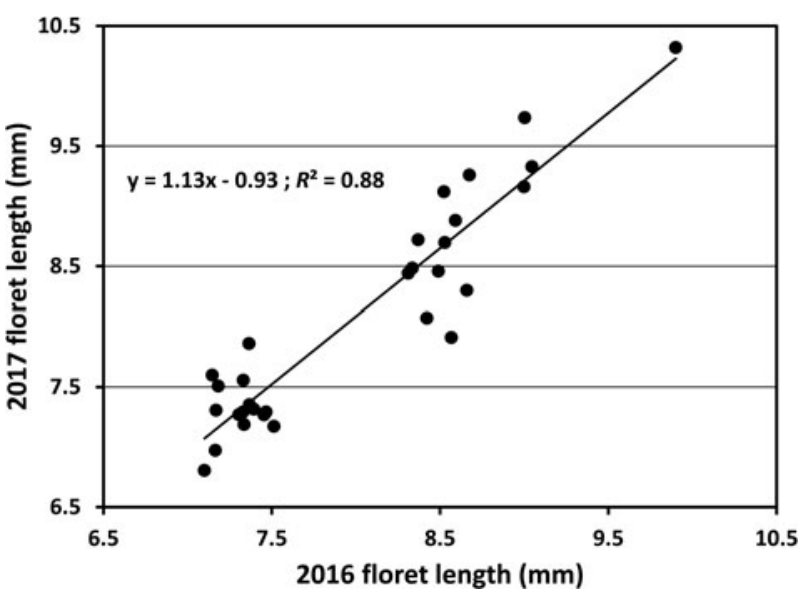

Fig. 2. Regression of mean floret lengths from 2017 to 2016 for $n=30$ inbred lines. Estimates for each year represent five replicates (plants) with five subsamples (florets) per plant.

distributed. As a result, the effect of floret size on pollinator visitation was assessed using simple linear regression (PROC REG).

\section{Results}

Sunflower maintainer lines sampled in 2016 showed significant variation in floret length $(F=30.11 ; \mathrm{df}=99,387$; $P<0.001$ ), but a near-continuous distribution of values from 6.8-9.9 mm and little plant-to-plant variation or measurement error (i.e. low coefficient of variation [CV]; see online Supplementary Table S1). Comparisons to HA 441, previously assessed as having shallow corollas, indicated one-third of the lines have similar $(P>0.050)$ mean floret length. Though whole floret lengths measured by an ImageJ macro are necessarily greater than corolla depths measured by hand, regression analysis indicates floret length is an adequate, simple proxy (corolla depth $=[0.70 \times$ floret length] $+0.28 ; n=30 ; R^{2}=0.78$; see online Supplementary Fig. S2).

Regression of mean floret lengths from 2017 to 2016 data showed concordance between the two data sets $\left(2017=[1.13 \times 2016]-0.93 ; n=30 ; R^{2}=0.88\right)$; in terms of year-to-year differences, the relative change in floret length estimates was about $3.50 \%$ across the 30 inbred lines (Fig. 2). Pollinator observations in the 2017 plots included a total of 7290 bees, with very few honey bees $(<1 \%)$ and bumble bees (2\%), but other abundant wild bees, with Melissodes trinodis Robertson and Andrena belianthi Robertson among the most common species. With all bee observations pooled for each line, floret length data from 2017 explained a majority of the variation in bee visitation to inbred lines, with a reduction of floret length of $2 \mathrm{~mm}$ more than doubling pollinator activity (bee visits $=[-34.55 \times$ floret length] + 368.70; $n=30 ; R^{2}=0.52$; Fig. 3). 


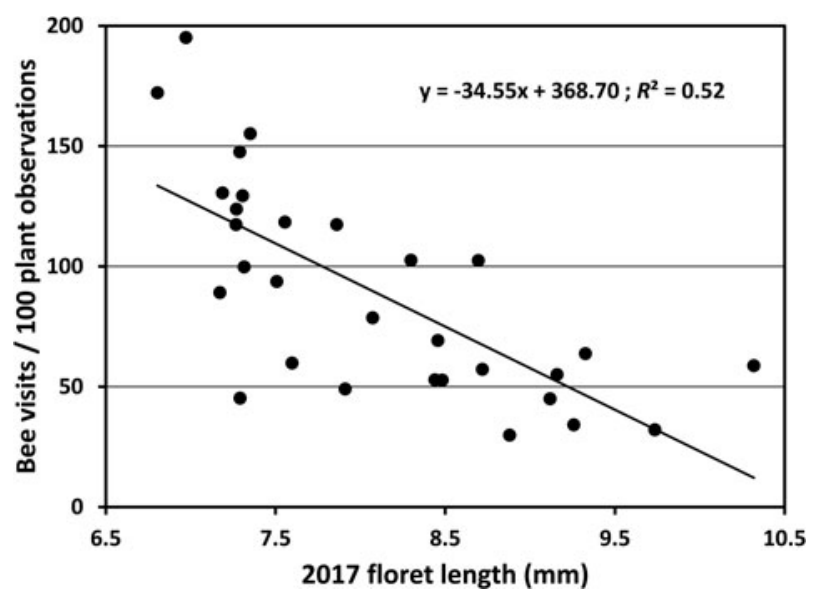

Fig. 3. Regression of bee visitation data onto floret length for $n=30$ inbred lines in 2017. Bee observations are adjusted for the total number of plants observed for each inbred line over ten days.

\section{Discussion}

Traits related to floral size, appearance, or floral rewards are associated with the number or duration of pollinator visits in many non-crop systems (Galen and Stanton, 1989; Manetas and Petropoulou, 2000; Kaczorowski et al., 2012). Recently, more attention has been paid to floral traits in cultivated crops, which represent an opportunity to improve both crop production and resources for pollinators. In some cropping systems, there is a realization that pollinators provide greater benefits than generally acknowledged. For example, while generally not considered pollinator-dependent, soybean (Glycine max [L.] Merr.) yields are increased by pollinators (Erickson, 1975a) and cultivars vary in floral traits that favour pollination (Erickson, 1975b); these and other similar observations have led Palmer et al. (2009) to advocate for pollinatorfriendly breeding of legumes. Bailes et al. (2015) more generally promote breeding for enhanced plant-pollinator interactions to improve yields and food security. Other recent examples of efforts to understand and enhance croppollinator interactions include Courcelles et al. (2013), who noted effects of flower morphology on honey bee pollination of cultivated blueberries (Vaccinium spp.); Soto et al. (2013), who found differences in nectar sugar content in onion (Allium cepa L.) and positive correlations between nectary volume and honey bee visitation; and Carruthers et al. (2017), who document variation in floral traits within and between oilseed rape (Brassica napus L.) breeding systems and suggest enhancement of nectar as a target for breeding programmes.

Floret size has often been considered an important part of sunflower-pollinator interactions (Cirnu et al., 1974; Shein et al., 1980; Sammataro et al., 1983; du Toit and
Coetzer, 1991). However, much of the previous research has not been peer-reviewed, lacked useful data, included few genotypes or used exclusively private germplasm, all of which limit the accessibility or value of the work, especially for subsequent efforts in breeding and genetics. Our data, which included observations on large numbers of public inbred lines, were intended to remedy some of the liabilities in previous work in sunflower pollination; results showed that floret lengths differed significantly between inbred lines, were consistent between years, and explained a majority of variation in visitation by wild pollinators.

In contrast to relatively minor differences in floret length of inbred lines between 2016 and 2017, Atlagić et al. (2003) found that year (i.e. environment) effects appeared to explain more variance in sunflower corolla length than genotype. Though a small number (6) of the 30 inbred lines measured in both 2016 and 2017 showed differences in measured floret length of more than $5 \%$, these changes were not consistently directional, with some lines increasing in size and others decreasing. Because of the effect that changes in plant density have to sunflower head size (Holt and Zentner, 1985), it is possible that variation in plant spacing explains the year-to-year changes, but insufficient data were collected to test this hypothesis. Another difference with previous research (Fell, 1986; Dag et al., 2002; Greenleaf and Kremen, 2006; Nderitu et al., 2008) is the near absence of honey bees foraging in the inbred lines in 2017, despite the location of hives $60 \mathrm{~m}$ away. Because of abundant pollen in the selected sunflower lines, limited honey bee foraging in sunflowers may reflect an avoidance of pollen, caused by a negative feedback mechanism within the colonies (Camazine, 1993). Also, the presence of alternate sources of pollen and nectar may determine honey bee visitation; abundant non-crop bee forage is a key attribute that makes North Dakota a favoured summering location for honey bees (Otto et al., 2016), and pollen-collecting honey bees appear to prefer other plants as pollen sources (Prasifka and Mallinger, unpublished data). Whatever the cause, previous results from the same location have found honey bee visitation to be inconsistent between years (Mallinger and Prasifka, 2017).

Understanding the importance of floret size to wild pollinators of sunflower and identifying highly attractive, short floret lines suggest potential to improve both the efficiency of hybrid seed production and the consistent, high yields of the resulting hybrids grown by sunflower producers. However, several potential limitations remain. First, because floret size differences of $1 \mathrm{~mm}$ or less may affect pollinator behaviour, it may be tedious to select for shorter florets without the use of genetic markers. Second, it is not clear to what degree pleiotropic effects on other traits may lead to undesirable trade-offs. For example, correlations among some sunflower seed traits are already known (Wills et al., 2010); if floret size and seed size are highly 
correlated, selection for shortened florets could be impractical when seed size is important (e.g. confection sunflowers) or limiting to oil yields if seed-to-hull ratios are affected. Third, the relationship between wild bee visitation and floret size provides only a partial explanation of behaviour and does not include information on how the honey bee, a key managed pollinator in sunflower hybrid seed production, responds to floret size. There is some variation in proboscis length in honey bees (Waddington and Herbst, 1987), but data on body size and proboscis length from many bee species (Cariveau et al., 2016) suggests limitations to honey bee foraging imposed by sunflowers with deep corollas may be similar to some common wild bees in sunflower (M. trinodis and Melissodes agilis Cresson; both long-tongued species) and less strong than others ( $A$. helianthi; a short-tongued bee).

The most efficient way to improve pollinator-sunflower interactions appears to be directly addressing the limitations noted above. Examining trait correlations and obtaining genetic markers should be cost-efficient given available sunflower genetic resources (Mandel et al., 2013) and success in understanding control of flower size in other plants (Krizek and Anderson, 2013). It also may be worthwhile to determine the most important pollinator species, a value that can logically be inferred by data on species' per-visit efficacy (successful pollinations per visit; Parker, 1981) and abundance in key growing areas; if relatively large bees are common and efficient pollinators, selection for minor reductions in floret size could provide a substantial improvement in pollination (i.e. there would be diminishing returns from further reducing floret size). Lastly, though quantifying other floral traits such as pollen and nectar content is slow and difficult, these traits may help explain residual variation in bee visitation (Somme et al., 2015) and contribute to improved sunflower pollination.

\section{Supplementary material}

The supplementary material for this article can be found at https://doi.org/10.1017/S1479262118000072

\section{Acknowledgements}

The authors thank Lisa Brown (USDA-ARS) for help in collecting floret size data and taking bee observations, Brady Koehler (USDA-ARS) for establishing and maintaining the 2016 field trials, and the North Dakota State University Agronomy Seed farm for providing land for field trials in 2017. Qing-Ming Gao (USDA-ARS) provided a constructive review of an earlier version of this manuscript. This publication is supported by the USDA Agricultural Research Service Long-Term Agroecosystem Research (LTAR) Network.

\section{References}

Atlagić J, Joksimović J, Sakač Z, Miklič V and Dušanić N (2003) Mode of inheritance and heritability of disc flower corolla length and nectar content in sunflower. Genetika 35: 59-65.

Bailes EJ, Ollerton J, Pattrick JG and Glover BJ (2015) How can an understanding of plant-pollinator interactions contribute to global food security? Current Opinion in Plant Biology 26: 72-79.

Camazine S (1993) The regulation of pollen foraging by honey bees: how foragers assess the colony's need for pollen. Behavioral Ecology and Sociobiology 32: 265-272.

Cariveau DP, Nayak GK, Bartomeus I, Zientek J, Ascher JS, Gibbs J and WInfree R (2016) The allometry of bee proboscis length and its uses in ecology. PLOS ONE 11: e0151482.

Carruthers JM, Cook SM, Wright GA, Osborne JL, Clark SJ, Swain JL and Haughton AL (2017) Oilseed rape (Brassica napus) as a resource for farmland insect pollinators: quantifying floral traits in conventional varieties and breeding systems. Global Change Biology Bioenergy 9: 1370-1379.

Cerrutti N and Pontet C (2016) Differential attractiveness of sunflower cultivars to the honeybee Apis mellifera L. Oilseed and Fats Crops and Lipids 23: D204.

Cirnu I, Dumitrache V and Hociota E (1974) La pollinisation du tournesol (Helianthus annuus L.) a l'aide des abilles - un facteur important pour l'augmentation de la production. In: Proceedings of the $6^{\text {th }}$ International Sunflower Conference. Paris, International Sunflower Association, pp. 695-700.

Courcelles DM, Button L and Elle E (2013) Bee visit rates vary with floral morphology among highbush blueberry cultivars (Vaccinium corymbosum L.). Journal of Applied Entomology 137: 693-701.

Dag A, Lior E and Afik O (2002) Pollination of confection sunflowers (Helianthus annuus) by honey bees (Apis mellifera L.). American Bee Journal 142: 443-445.

DeGrandi-Hoffman G and Chambers M (2006) Effects of honey bee (Hymenoptera: Apidae) foraging on seed set in selffertile sunflowers (Helianthus annuus L.). Environmental Entomology 35: 1103-1108.

DeGrandi-Hoffman G and Watkins JC (2000) The foraging activity of honey bees Apis mellifera and non-Apis bees on hybrid sunflowers (Helianthus annuus) and its influence on cross-pollination and seed set. Journal of Apicultural Research 39: 37-45.

du Toit AP and Coetzer LA (1991) Difference in potential attractiveness to bees of seventeen South African sunflower (Helianthus anuus) cultivars. Acta Horticulturae 288: 288-293.

Erickson EH (1975a) Effect of honey bees on yield of three soybean cultivars. Crop Science 15: 84-86.

Erickson EH (1975b) Variability of floral characteristics influences honey bee visitation to soybean blossoms. Crop Science 15: $767-771$.

FAO [Food and Agriculture Organization of the United Nations] (2017) FAO Food Outlook: Oilseeds. FAO, Rome, Italy. http:// www.fao.org/fileadmin/templates/est/COMM_MARKETS_ MONITORING/Oilcrops/Documents/Food_outlook_oilseeds/ FO_June_2017.pdf [Accessed 3 October 2017].

Fell RD (1986) Foraging behaviors of Apis mellifera L. and Bombus spp. on oilseed sunflower (Helianthus annuus L.). Journal of the Kansas Entomological Society 59: 72-81.

Galen C and Stanton ML (1989) Bumble bee pollination and floral morphology: factors influencing pollen dispersal in the 
alpine sky pilot, Polemonium viscosum (Polemoniaceae). American Journal of Botany 76: 419.

Gandhi SD, Heesacker AF, Freeman CA, Argyris J, Bradford K and Knapp SJ (2005) The self-incompatibility locus (s) and quantitative trait loci for self-pollination and seed dormancy in sunflower. Theoretical and Applied Genetics 111: 619-629.

Greenleaf SS and Kremen C (2006) Wild bees enhance honey bees' pollination of hybrid sunflower. Proceedings of the National Academy of Sciences of the United States of America 103: 13890-13895.

Heiser CB, Smith DM, Clevenger SB and Martin WC (1969) The North American sunflowers (Helianthus). Memoirs of the Torrey Botanical Club 22: 1-218.

Holt NW and Zentner RP (1985) Effect of plant density and row spacing on agronomic performance and economic returns of nonoilseed sunflower in Southeastern Saskatchewan. Canadian Journal of Plant Science 65: 501-509.

Inouye DW (1980) The effect of proboscis and corolla tube lengths on patterns and rates of flower visitation by bumblebees. Oecologia 45: 197-201.

Kaczorowski RL, Seliger AR, Gaskett AC, Wigsten SK and Raguso RA (2012) Corolla shape vs. size in flower choice by a nocturnal hawkmoth pollinator: corolla shape and size in hawkmoth choice. Functional Ecology 26: 577-587.

Krizek BA and Anderson JT (2013) Control of flower size. Journal of Experimental Botany 64: 1427-1437.

Mandel JR, Nambeesan S, Bowers JE, Marek LF, Ebert D, Rieseberg LH, Knapp SJ and Burke JM (2013) Association mapping and the genomic consequences of selection in sunflower. PLoS Genetics 9: e1003378.

Manetas Y and Petropoulou Y (2000) Nectar amount, pollinator visit duration and pollination success in the Mediterranean shrub Cistus creticus. Annals of Botany 86: 815-820.

Mallinger RE and Prasifka JR (2017) Bee visitation rates to cultivated sunflowers increase with the amount and accessibility of nectar sugars. Journal of Applied Entomology 7: 561-573.

Mallinger RE and Prasifka JR (2018) Benefits of insect pollination to confection sunflowers differ across plant genotypes. Crop Science 57: 3264-3272.

Miller JF and Gulya TJ (2006) Registration of two restorer (RHA 439 and RHA 440) and one maintainer (HA 441) Sclerotinia tolerant oilseed sunflower germplasms. Crop Science 46: 482-483.

Neff J L and Simpson BB (1990) The roles of phenology and reward structure in the pollination biology of wild sunflower (Helianthus annuus L., Asteraceae). Israel Journal of Botany 39: 197-216.

Nderitu J, Nyamasyo G, Kasina M and Oronje ML (2008) Diversity of sunflower pollinators and their effect on seed yield in Makueni District, Eastern Kenya. Spanish Journal of Agricultural Research 6: 271-278.
Otto CRV, Roth CL, Carlson BL and Smart MD (2016) Land-use change reduces habitat suitability for supporting managed honey bee colonies in the northern great plains. Proceedings of the National Academy of Sciences of the United States of America 113: 10430-10435.

Palmer RG, Perez PT, Ortiz-Perez E, Maalouf F and José Suso M (2009) The role of crop-pollinator relationships in breeding for pollinator-friendly legumes: from a breeding perspective. Euphytica 170: 35-52.

Parker FD (1981) How efficient are bees in pollinating sunflowers? Journal of the Kansas Entomological Society 54, 61-67.

Peat J, Tucker J and Goulson D (2005) Does intraspecific size variation in bumblebees allow colonies to efficiently exploit different flowers? Ecological Entomology 30: 176-181.

Pham-Delegue MH, Etievant P, Guichard E, Marilleau R, Douault PH, Chauffaille J and Masson C (1990) Chemicals involved in honeybee-sunflower relationship. Journal of Chemical Ecology 16: 3053-3065.

Sammataro D, Erickson EH and Garment M (1983) Intervarietal structural differences of sunflower (Helianthus annuus) florets and their importance to honey bee visitation. In: Proceedings of the 5th Sunflower Research Workshop. Bismarck, ND, USA National Sunflower Association, pp. 4-6.

SAS Institute Inc. (2016) Base SAS 9.4 Procedures Guide: Statistical Procedures, 5th edn. Cary, NC: SAS Institute Inc.

Schneider CA, Rasband WS and Eliceiri KW (2012) NIH image to ImageJ: 25 years of image analysis. Nature Methods 9: 671--675.

Shein SE, Sargent SJ and Miko J (1980) An evaluation of differential attractiveness of sunflower genotypes to honey bees. In Proceedings of the 9 th International Sunflower Conference, 216-220. Torremolinos, Spain.

Somme L, Vanderplanck M, Michez D, Lombaerde I, Moerman R, Wathelet B, Wattiez R, Lognay G and Jacquemart AL (2015) Pollen and nectar quality drive the major and minor floral choices of bumble bees. Apidologie 46: 92-106.

Soto VC, Maldonado IB, Gil RA, Peralta IE, Silva MF and Galmarini CR (2013) Nectar and flower traits of different onion male sterile lines related to pollination efficiency and seed yield of F1 hybrids. Journal of Economic Entomology 106: 1386-1394.

Tepedino VJ and Parker FD (1982) Interspecific differences in the relative importance of pollen and nectar to bee species -foraging on sunflowers. Environmental Entomology 11: $246-250$.

Waddington KD and Herbst LH (1987) Body size and the functional length of the proboscis of honey bees. The Florida Entomologist 70: 124.

Wills DM, Abdel-Haleem H, Knapp SJ and Burke JM (2010) Genetic architecture of novel traits in the Hopi sunflower. Journal of Heredity 101: 727-736. 